Supporting Information

\title{
Perylene Bisimide-Based Luminescent Liquid Crystals with Tunable Solid-State Light Emission
}

\author{
Bin $\mathrm{Mu},{ }^{\dagger}$ Zhelin Zhang, ${ }^{\dagger}$ Xuhong Quan, Xiangnan Hao, Wei Tian*
}

Shanxi Key Laboratory of Macromolecular Science and Technology, MOE Key Laboratory of Material

Physics and Chemistry under Extraordinary Conditions, School of Chemistry and Chemical Engineering, Northwestern Polytechnical University, Xi'an, 710072, China.

†These authors contributed equally.

*E-mail: happytw_3000@nwpu.edu.cn 


\section{Materials and Measurements}

Materials. 4-Formylbenzonitrile ( $>98 \%$, TCI), dicyandiamide ( $>98 \%, \mathrm{TCI})$, pivaloyl chloride ( $98 \%$, Innochem), lithium aluminum hydride (10\% in tetrahydrofuran, TCI), trimethylsilyl cyanide (97\%, Innochem), and perylene-3,4,9,10-tetracarboxylicdianhydride (98\%, TCI) were used as received. All other chemical reagents were commercially available and used as received.

Measurements. ${ }^{1} \mathrm{H}$ NMR and ${ }^{13} \mathrm{C}$ NMR spectra in solution were obtained from Bruker Avance 400 instruments. Multiplicities are denoted as follows: $\mathrm{s}=$ singlet, $\mathrm{d}=$ doublet, $\mathrm{t}=$ triplet, and $\mathrm{m}=$ multiplet. Mass spectra was recorded on a LCMS-2020 single quadrupole equipped with an electrospray ionization (ESI) source interface (Shimadzu). Matrix-assisted laser desorption/ionization time-of-flight mass spectrometry (MALDI-TOF-MS) was performed on an Absciex MALDI TOFTOF 4800 plus instrument. Elemental analyses were carried out with an Elementar Vario Micro. Fourier transform infrared spectra (FT-IR) were recorded on a NICOLET iS50 infrared spectrometer. Thermal gravimetric analysis (TGA) was carried out on a Netzsch simultaneous thermal analysis STA $449 \mathrm{~F} 3$ instrument under argon atmosphere at a flow rate of $40 \mathrm{~mL} \mathrm{~min}^{-1}$ with the scanning rate of $20^{\circ} \mathrm{C}$ $\min ^{-1}$ from $35^{\circ} \mathrm{C}$ to $600{ }^{\circ} \mathrm{C}$. Differential scanning calorimetry (DSC) thermograms were recorded on a Netzsch DSC 214 system equipped with a cooling accessory and under nitrogen atmosphere at a flow rate of $20 \mathrm{~mL} \mathrm{~min}^{-1}$. Typically, about $5 \mathrm{mg}$ of the solid sample was encapsulated in a sealed aluminum pan with an identical empty pan as the reference with a heating or cooling rate of $10^{\circ} \mathrm{C} \mathrm{min}^{-1}$. Polarized optical microscopy (POM) was adopted to characterize thermal transitions, observe and photograph textures with a Nikon E400POL microscope equipped with an Instec HCS302 hot and cold stage. Xray scattering experiments were performed with Anton Paar SAXSpoint 2.0 small-angle X-ray scattering instruments. The scattering vector $q$ is defined as $4 \pi \sin \theta / \lambda$, where the wavelength $\lambda$ is 0.1542 $\mathrm{nm}$ of $\mathrm{Cu}-\mathrm{K}_{\alpha}$ radiation and $2 \theta$ is the scattering angle. X-ray diffraction experiment was conducted on a Bruker D8 discover X-ray diffracmeter with $\mathrm{Co} \mathrm{K}_{\alpha}$ as the radiation. Ultraviolet visible (UV-vis) absorption spectra were recorded on a Shimadzu UV-2550 spectrometer. Fluorescence spectra, absolute quantum yield and time-resolved fluorescence lifetime experiments were recorded with an Edinburgh FLS1000 transient steady-state fluorescence spectrometer, where the time-resolved lifetime was obtained by adopting a $340 \mathrm{~nm}$ picosecond pulsed excitation source. 


\section{Preparation of the Hydrogen-Bonded Complex}
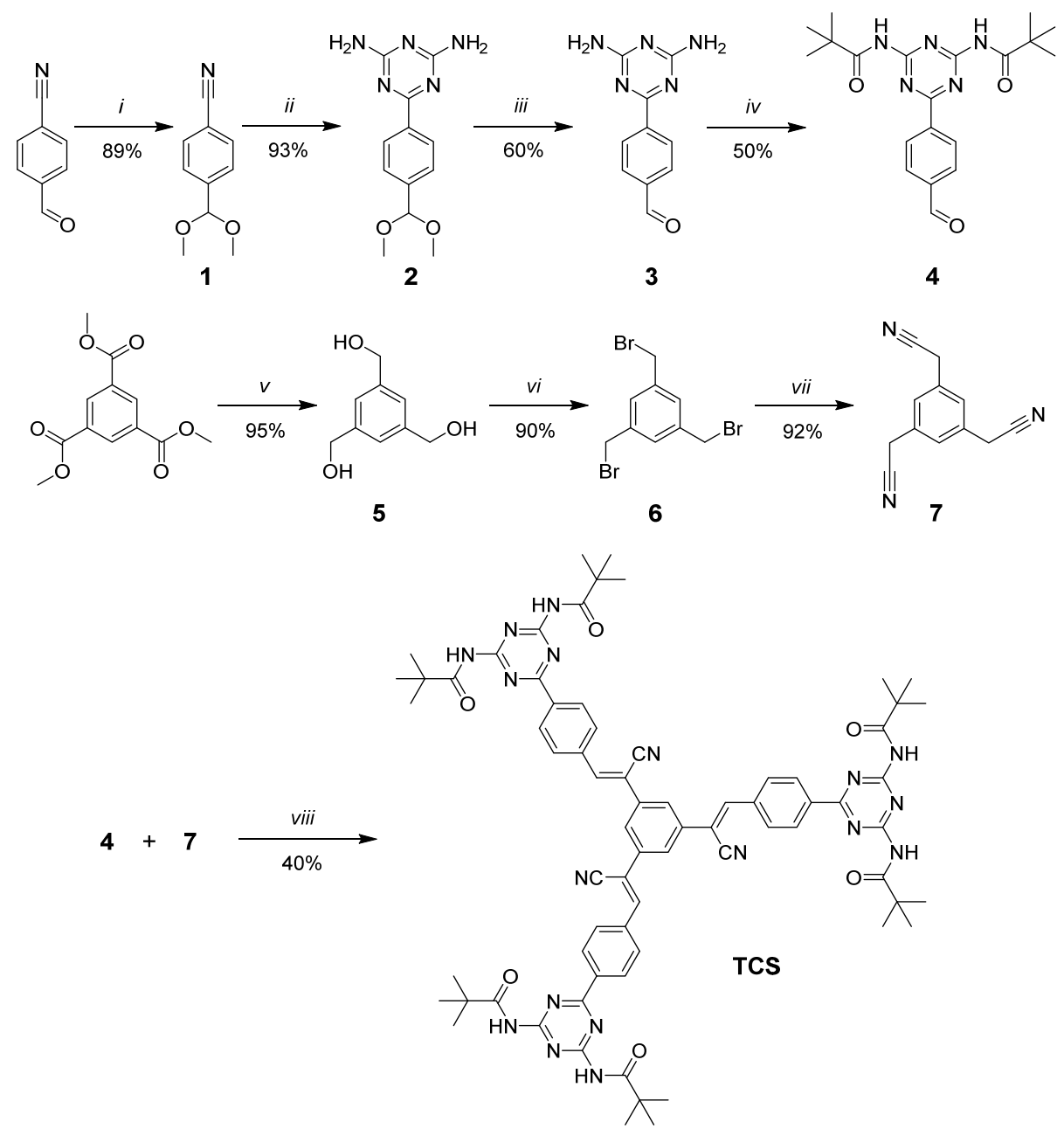

Scheme S1. Synthesis of the TCS. Reagents and conditions: (i) trimethyl orthoformate, pyridinium $p$ toluenesulfonate (PPTS), methanol, $75^{\circ} \mathrm{C}, 4 \mathrm{~h}$; (ii) dicyandiamide, $\mathrm{KOH}, 2$-methoxyethanol, $80{ }^{\circ} \mathrm{C}$, $12 \mathrm{~h}$; (iii) $\mathrm{HCl}$, methanol, $146{ }^{\circ} \mathrm{C}, 12 \mathrm{~h}$; (iv) pivaloyl chloride, pyridine, $120{ }^{\circ} \mathrm{C}, 120 \mathrm{~h}$; (v) LiAlH4, THF, $25{ }^{\circ} \mathrm{C}$; (vi) $\mathrm{PBr}_{3}$, dichloromethane, $80{ }^{\circ} \mathrm{C}, 5 \mathrm{~h}$; (vii) trimethylsilyl cyanide (TMSCN), tetrabutylammonium fluoride, acetonitrile, $25^{\circ} \mathrm{C}, 48 \mathrm{~h}$; (viii) tetrabutylammonium hydroxide, ethanol, $45^{\circ} \mathrm{C}, 20 \mathrm{~min}$.

4-(dimethoxymethyl)benzonitrile (1). A mixture of 4-formylbenzonitrile (2 g, $15.3 \mathrm{mmol})$, trimethyl orthoformate $(16.8 \mathrm{~mL}, 20 \mathrm{mmol})$, and pyridinium $p$-toluenesulfonate (PPTS, $0.804 \mathrm{~g}, 3.2 \mathrm{mmol})$ in $40 \mathrm{~mL}$ methanol was stirred at $75{ }^{\circ} \mathrm{C}$ under nitrogen atmosphere for $4 \mathrm{~h}$. After cooling to room temperature, the reaction mixture was poured into saturated $\mathrm{NaHCO}_{3}$ aqueous solution and then extracted with ethyl acetate to give a light yellow oil. The crude product was finally purified by silica- 
gel column chromatography using mixed solvents of petroleum ether/dichloromethane $(1: 1, \mathrm{v} / \mathrm{v})$ as the eluent to give a desired product (2.4 g) in light yellow viscous liquid. Yield 89\%. ${ }^{1} \mathrm{H}$ NMR (400 $\left.\mathrm{MHz}, \mathrm{CDCl}_{3}\right): \delta(\mathrm{ppm})=7.68(\mathrm{~d}, 2 \mathrm{H}, J=6.4 \mathrm{~Hz}), 7.59(\mathrm{~d}, 2 \mathrm{H}, J=6.8 \mathrm{~Hz}), 5.44(\mathrm{~s}, 4 \mathrm{H}), 3.34(\mathrm{~d}, 6 \mathrm{H}$, $J=4 \mathrm{~Hz})$.

6-(4-(dimethoxymethyl)phenyl)-1,3,5-triazine-2,4-diamine (2). A mixture of 1 (2.4 g, $13.6 \mathrm{mmol})$, dicyandiamide $(2.6 \mathrm{~g}, 31.5 \mathrm{mmol})$ and $\mathrm{KOH}(0.4 \mathrm{~g}, 7.5 \mathrm{mmol})$ in $20 \mathrm{~mL}$ 2-methoxyethanol was stirred at $80{ }^{\circ} \mathrm{C}$ under nitrogen atmosphere overnight. After removal of the solvent, the white solid was purified by silica-gel column chromatography using ethyl acetate as the eluent to give a desired product $(3.3 \mathrm{~g})$ in white solid. Yield 93\%. ${ }^{1} \mathrm{H}$ NMR (400 MHz, dimethyl sulfoxide- $\left.d 6\right): \delta(\mathrm{ppm})=8.25(\mathrm{~d}, 2 \mathrm{H}$, $J=6.4 \mathrm{~Hz}), 7.48(\mathrm{~d}, 2 \mathrm{H}, J=6.8 \mathrm{~Hz}), 6.77(\mathrm{~s}, 4 \mathrm{H}), 5.45(\mathrm{~s}, 1 \mathrm{H}), 3.26(\mathrm{~s}, 6 \mathrm{H})$.

4-(4,6-diamino-1,3,5-triazin-2-yl)benzaldehyde (3). A solution of 2 (3.3 g, $12.6 \mathrm{mmol})$ and $2 \mathrm{~mL}$ concentrated $\mathrm{HCl}$ aqueous solution in $10 \mathrm{~mL}$ methanol was stirred at $146{ }^{\circ} \mathrm{C}$ overnight. After cooling to room temperature, the reaction mixture was neutralized with $\mathrm{KOH}$ until $\mathrm{pH}$ about 7. The precipitate was collected by filtration and then washed with water to give a desired product ( $1.6 \mathrm{~g})$ in white solid. Yield 60\%. ${ }^{1} \mathrm{H}$ NMR (400 MHz, dimethyl sulfoxide- $\left.d_{6}\right): \delta(\mathrm{ppm})=10.09(\mathrm{~s}, 1 \mathrm{H}), 8.43(\mathrm{~d}, 2 \mathrm{H}, J=6.4$ $\mathrm{Hz}), 8.01(\mathrm{~d}, 2 \mathrm{H}, J=6.8 \mathrm{~Hz}), 6.89(\mathrm{~s}, 4 \mathrm{H})$.

$N, N^{\prime}$-(6-(4-formylphenyl)-1,3,5-triazine-2,4-diyl)bis(2,2-dimethylpropanamide) (4). To a solution of 3 (1.6 g, $7.4 \mathrm{mmol})$ in $20 \mathrm{~mL}$ pyridine, pivaloyl chloride (6 mL, $37 \mathrm{mmol})$ was added slowly and then allowed to stir at $120{ }^{\circ} \mathrm{C}$ for $120 \mathrm{~h}$. The reaction mixture was cooled down to room temperature and was then poured into $50 \mathrm{~mL}$ water. After extraction with dichloromethane, the crude product was dissolved in a small amount of dichloromethane and then dropped into a large amount of hexane. The generated precipitate was collected by filtration. The crude product was purified by silica-gel column chromatography using mixed solvents of dichloromethane/ethyl acetate $(6: 1, \mathrm{v} / \mathrm{v})$ as the eluent to give a desired product $(1.4 \mathrm{~g})$ in white solid. Yield 50\%. ${ }^{1} \mathrm{H}$ NMR (400 MHz, dimethyl sulfoxide- $\left.d_{6}\right): \delta$ $(\mathrm{ppm})=10.34(\mathrm{~s}, 2 \mathrm{H}), 10.14(\mathrm{~s}, 1 \mathrm{H}), 8.63(\mathrm{~d}, 2 \mathrm{H}, J=6.4 \mathrm{~Hz}), 8.12(\mathrm{~d}, 2 \mathrm{H}, J=6.8 \mathrm{~Hz}), 1.27(\mathrm{~s}, 18 \mathrm{H})$.

2,2',2'-(benzene-1,3,5-triyl)triacetonitrile (7). A solution of 1,3,5-tris(bromomethyl)benzene (6, 1 $\mathrm{g}, 2.8 \mathrm{mmol})$, trimethylsilyl cyanide $(1.6 \mathrm{~g}, 16.1 \mathrm{mmol})$ and tetrabutylammonium fluoride $(13 \mathrm{~g}, 49.7$ $\mathrm{mmol}$ ) in $20 \mathrm{~mL}$ acetonitrile was stirred at room temperature for $48 \mathrm{~h}$. After removal of the solvent, 
dichloromethane was added and washed with water. Finally, the crude product was purified by silicagel column chromatography using petroleum ether as the eluent to give a desired product $(0.5 \mathrm{~g})$ in white solid. Yield 92\%. ${ }^{1} \mathrm{H}$ NMR (400 MHz, $\left.\mathrm{CDCl}_{3}\right): \delta(\mathrm{ppm})=7.33$ (s, 3H), $3.82(\mathrm{~s}, 6 \mathrm{H})$.

Tricyanotristyrylbenzene (TCS). A solution of 4 (2.6 g, $6.77 \mathrm{mmol}), 7(0.4 \mathrm{~g}, 2.05 \mathrm{mmol})$ and 1.5 $\mathrm{mL}$ tetrabutylammonium hydroxide $\left(10 \%\right.$ in methanol) in $20 \mathrm{~mL}$ ethanol was stirred at $45^{\circ} \mathrm{C}$ for 20 min. After collection of the precipitate by filtration, the crude product was purified by silica-gel column chromatography using chloroform as the eluent to give a desired product $(1.1 \mathrm{~g})$ in bright yellow solid. Yield 40\%. ${ }^{1} \mathrm{H}$ NMR (400 MHz, $\left.\mathrm{CDCl}_{3}\right): \delta(\mathrm{ppm})=8.74(\mathrm{~s}, 6 \mathrm{H}), 8.67(\mathrm{~d}, 6 \mathrm{H}, J=8.4 \mathrm{~Hz}), 8.08(\mathrm{~d}, 6 \mathrm{H}$, $J=8.5 \mathrm{~Hz}), 8.03(\mathrm{~s}, 3 \mathrm{H}), 7.77(\mathrm{~s}, 3 \mathrm{H}), 1.38(\mathrm{~s}, 54 \mathrm{H}) .{ }^{13} \mathrm{C} \mathrm{NMR}\left(100 \mathrm{MHz}, \mathrm{CDCl}_{3}\right): \delta(\mathrm{ppm})=176.70$, $172.73,164.58,143.54,137.29,137.03,136.45,129.73,124.60,117.30,111.63,40.77,27.22$. ESIMS $(m / z):[\mathrm{M}+\mathrm{Na}]^{+}$calcd 1313.62, found 1313.90. Elemental analysis: Calcd for $\mathrm{C}_{72} \mathrm{H}_{78} \mathrm{~N}_{18} \mathrm{O}_{6} \mathrm{C}$ $66.96 \%$, H 6.09\%, N 19.52\%, O 7.43\%; Found. C 66.51\%, H 6.18\%.

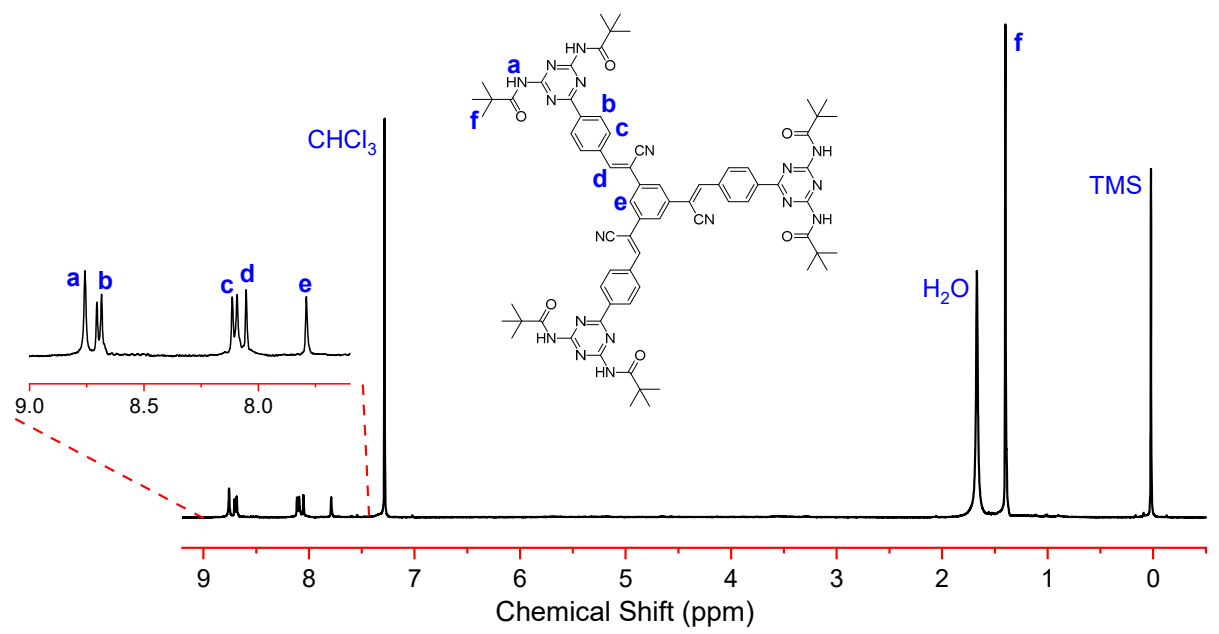

Figure S1. Molecular characterization of Z,Z,Z-TCS by ${ }^{1} \mathrm{H}$ NMR spectrum. 


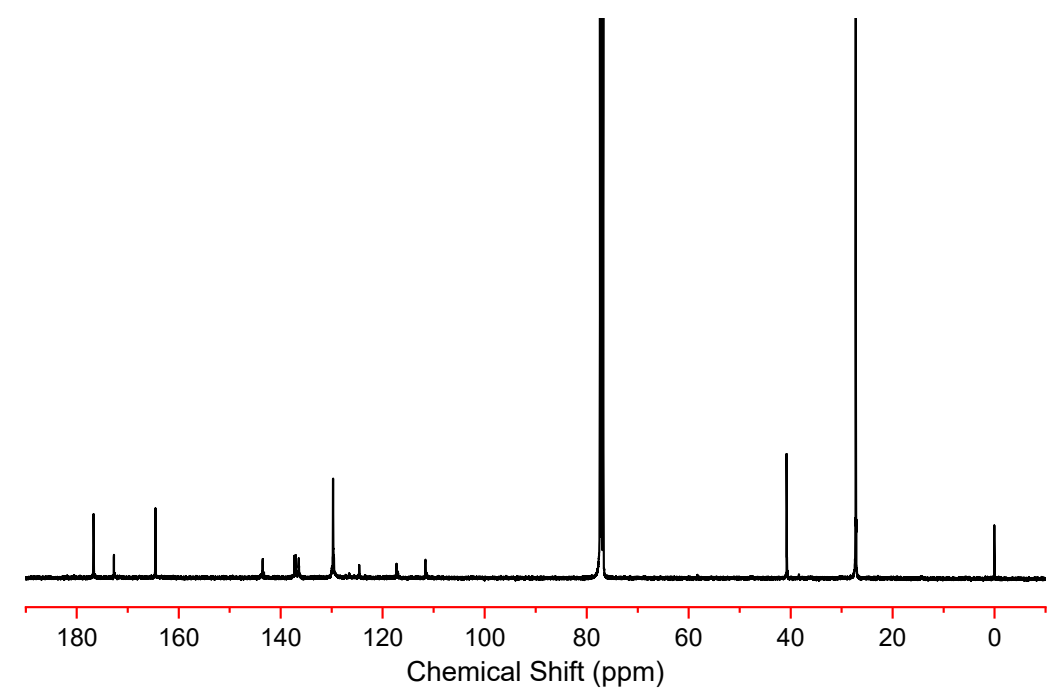

Figure S2. Molecular characterization of $Z, Z, Z-\mathrm{TCS}$ by ${ }^{13} \mathrm{C}$ NMR spectrum.

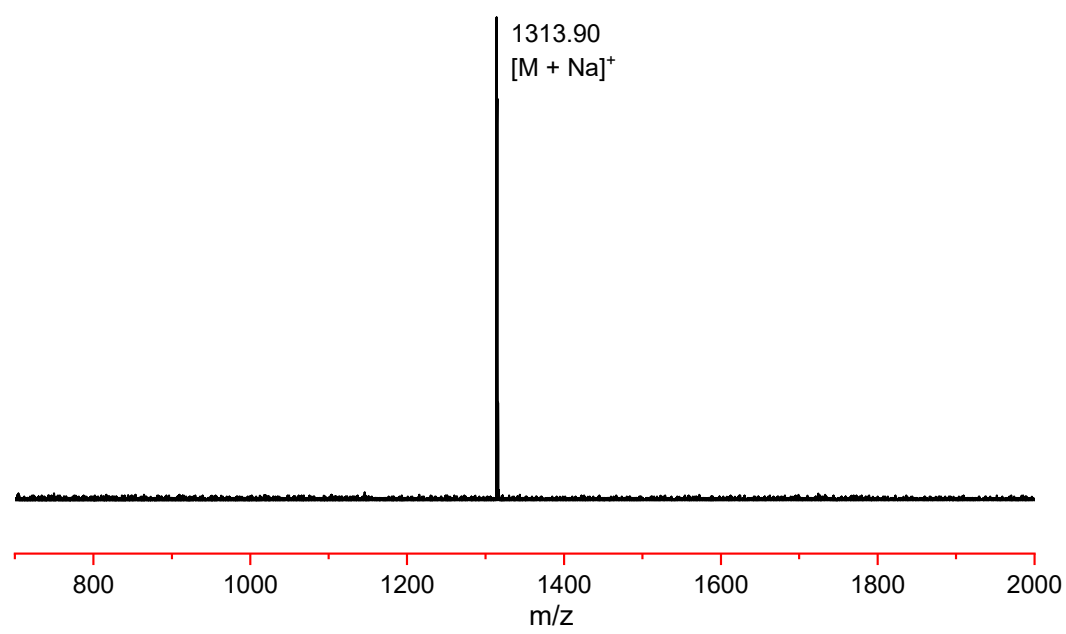

Figure S3. Molecular characterization of Z,Z,Z-TCS by ESI-MS spectrum.

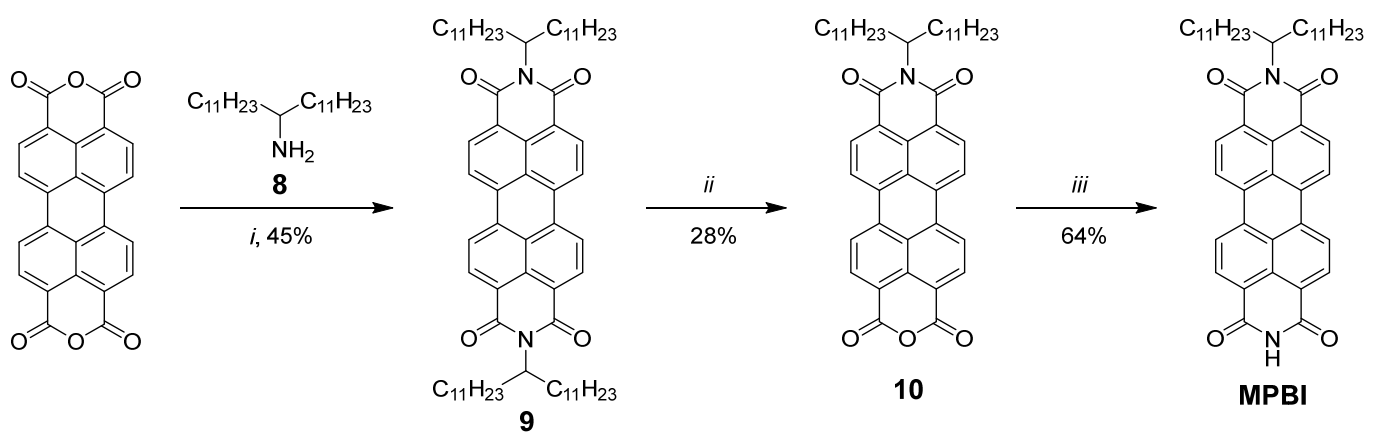

Scheme S2. Synthesis of the MPBI. Reagents and conditions: (i) imidazole, $180{ }^{\circ} \mathrm{C}, 5 \mathrm{~h}$; (ii) $\mathrm{KOH}$, tertiary butanol, $105^{\circ} \mathrm{C}, 30 \mathrm{~min}$; (iii) $\mathrm{NH}_{4} \mathrm{OH}, \mathrm{K}_{2} \mathrm{CO}_{3}, 90^{\circ} \mathrm{C}, 2 \mathrm{~h}$. 
1-Dodecyltridecylamine (8). A mixture of 12-tricosanone (17.8 g, $52.5 \mathrm{mmol})$, ammonium acetate $(40.1 \mathrm{~g}, 520 \mathrm{mmol})$ and sodium cyanoborohydride $(2.3 \mathrm{~g}, 38 \mathrm{mmol})$ in $75 \mathrm{~mL}$ methanol was stirred at room temperature for $48 \mathrm{~h}$. The mixture was quenched by $6 \mathrm{~mL}$ concentrated $\mathrm{HCl}$ aqueous solution, and then $500 \mathrm{~mL}$ water was added and $\mathrm{KOH}$ was used to adjust the $\mathrm{pH}$ about 10. Finally, extraction with dichloromethane to give a desired product $(9.0 \mathrm{~g})$ in white solid. Yield 86\%. ${ }^{1} \mathrm{H}$ NMR (400 MHz, $\left.\mathrm{CDCl}_{3}\right): \delta(\mathrm{ppm})=2.73(\mathrm{~m}, 1 \mathrm{H}), 1.51-1.18(\mathrm{~m}, 40 \mathrm{H}), 0.89(\mathrm{t}, 6 \mathrm{H}, J=7.0 \mathrm{~Hz})$.

$N, N$ '-bis(1-dodecyltridecyl)perylene-3,4,9,10-tetracarboxylbisimide (9). A mixture of perylene3,4,9,10-tetracarboxylicdianhydride $(7.4 \mathrm{~g}, 18.9 \mathrm{mmol})$ and 1-dodecyltridecylamine $(\mathbf{8}, 15.3 \mathrm{~g}, 45.2$ $\mathrm{mmol}$ ) in $30 \mathrm{~g}$ imidazole was stirred at $180{ }^{\circ} \mathrm{C}$ for $5 \mathrm{~h}$. The reaction mixture was cooled to room temperature, and then $200 \mathrm{~mL}$ ethanol and $800 \mathrm{~mL} 2 \mathrm{~mol} / \mathrm{L} \mathrm{HCl}$ aqueous solution was added, which was allowed for stirring overnight. The dark red precipitate was filtered and rinsed thoroughly with water, and dried at $120{ }^{\circ} \mathrm{C}$ to give a desired product $(6.4 \mathrm{~g})$ in red solid. Yield $45 \% .{ }^{1} \mathrm{H}$ NMR (400 $\left.\mathrm{MHz}, \mathrm{CDCl}_{3}\right): \delta(\mathrm{ppm})=8.67(\mathrm{~m}, 8 \mathrm{H}), 5.20(\mathrm{~m}, 2 \mathrm{H}), 2.34-2.19(\mathrm{~m}, 4 \mathrm{H}), 1.94-1.80(\mathrm{~m}, 4 \mathrm{H}), 1.45-1.12$ $(\mathrm{m}, 72 \mathrm{H}), 0.86(\mathrm{t}, 12 \mathrm{H}, J=7.0 \mathrm{~Hz})$.

$N$-(1-dodecyltridecyl)perylene-3,4,9,10-tetracarboxyl-3,4-anhydride-9,10-imide (10). A mixture of $9(8.8 \mathrm{~g}, 8.5 \mathrm{mmol}), \mathrm{KOH}(3.3 \mathrm{~g}, 59 \mathrm{mmol})$ in $330 \mathrm{~mL}$ tertiary butanol was stirred at $105{ }^{\circ} \mathrm{C}$ for 30 min. The reaction mixture was cooled to room temperature, and then $175 \mathrm{~mL}$ acetic acid and $90 \mathrm{~mL} 2$ $\mathrm{mol} / \mathrm{L} \mathrm{HCl}$ aqueous solution was added, which was allowed for stirring overnight. The dark red precipitate was filtered and rinsed thoroughly with water, and dried at $130{ }^{\circ} \mathrm{C}$ to give a red solid. This solid was suspended in $330 \mathrm{~mL} 10 \% \mathrm{~K}_{2} \mathrm{CO}_{3}$ solution and heated to reflux for $30 \mathrm{~min}$. After filtration, and the filter cake was rinsed with $300 \mathrm{~mL} 2 \mathrm{~mol} / \mathrm{L} \mathrm{HCl}$ aqueous solution, then rinsed thoroughly with $200 \mathrm{~mL}$ water and dried at $130^{\circ} \mathrm{C}$ to give a red solid. The solid was then suspended in $100 \mathrm{~mL}$ boiling water, and trimethylamine was added until a dark purple solution of the desired product formed. After filtration, the dark purple filtrate was acidified with $300 \mathrm{~mL} 2 \mathrm{~mol} / \mathrm{L} \mathrm{HCl}$ aqueous solution and stirred overnight. The precipitate was collected by filtration and rinsed thoroughly with water. Finally, the crude product was purified by silica-gel column chromatography using dichloromethane as the eluent to give a desired product $(1.35 \mathrm{~g})$ in red solid. Yield $28 \% .{ }^{1} \mathrm{H}$ NMR $\left(400 \mathrm{MHz}, \mathrm{CDCl}_{3}\right): \delta(\mathrm{ppm})=8.71$ $(\mathrm{m}, 8 \mathrm{H}), 5.20(\mathrm{~m}, 1 \mathrm{H}), 2.32-2.20(\mathrm{~m}, 2 \mathrm{H}), 1.95-1.83(\mathrm{~m}, 2 \mathrm{H}), 1.44-1.14(\mathrm{~m}, 36 \mathrm{H}), 0.86(\mathrm{t}, 6 \mathrm{H}, J=6.96$ $\mathrm{Hz})$. 
$N$-(1-dodecyltridecyl)perylene-3,4,9,10-tetracarboxylic-bisimide (MPBI). A mixture of 10 (1.11 g, $1.56 \mathrm{mmol}$ ) in $90 \mathrm{~mL} 3 \%$ ammonia water solution was stirred at $90{ }^{\circ} \mathrm{C}$ for $1 \mathrm{~h}$, and $6 \mathrm{~g} \mathrm{~K}_{2} \mathrm{CO}_{3}$ was added and then the mixture was stirred for another $2 \mathrm{~h}$ at $90{ }^{\circ} \mathrm{C}$. After cooling to room temperature, the precipitate was collected by filtration and washed with aqueous $\mathrm{K}_{2} \mathrm{CO}_{3}$ solution. The solid residue wad suspended in $1 \mathrm{~mol} / \mathrm{L} \mathrm{HCl}$ aqueous solution, and allowed for stirring overnight. The red solid was collected by filtration again and dried under vacuum. The crude product was purified by silica-gel column chromatography using chloroform/ethanol $(20: 1, \mathrm{v} / \mathrm{v})$ as the eluent to give a desired product $(0.57 \mathrm{~g})$ in red solid. Yield 64\%. ${ }^{1} \mathrm{H}$ NMR $\left(400 \mathrm{MHz}, \mathrm{CDCl}_{3}\right): \delta(\mathrm{ppm})=8.70(\mathrm{~m}, 8 \mathrm{H}), 5.20(\mathrm{~m}, 1 \mathrm{H})$, 2.34-2.20 (m, 2H), 1.95-1.82 (m, 2H), 1.44-1.10 (m, 36H), $0.86(\mathrm{t}, 6 \mathrm{H}, J=7.00 \mathrm{~Hz}) .{ }^{13} \mathrm{C}$ NMR $(100$ $\left.\mathrm{MHz}, \mathrm{CDCl}_{3}\right): \delta(\mathrm{ppm})=163.07,135.32,134.06,131.85,131.20,130.68,129.46,126.82,126.25$, 123.35, 122.93, 54.88, 32.36, 31.91, 29.62, 27.00, 22.68, 14.12. MALDI-TOF-MS $(\mathrm{m} / \mathrm{z}):[\mathrm{M}+\mathrm{H}]^{+}$ calcd 713.43, found 713.20. Elemental analysis: Calcd for $\mathrm{C}_{47} \mathrm{H}_{56} \mathrm{~N}_{2} \mathrm{O}_{4} \mathrm{C} 79.18 \%, \mathrm{H} 7.92 \%$, N 3.93\%, O $8.98 \%$; Found. C $79.32 \%$, H 9.05\%.

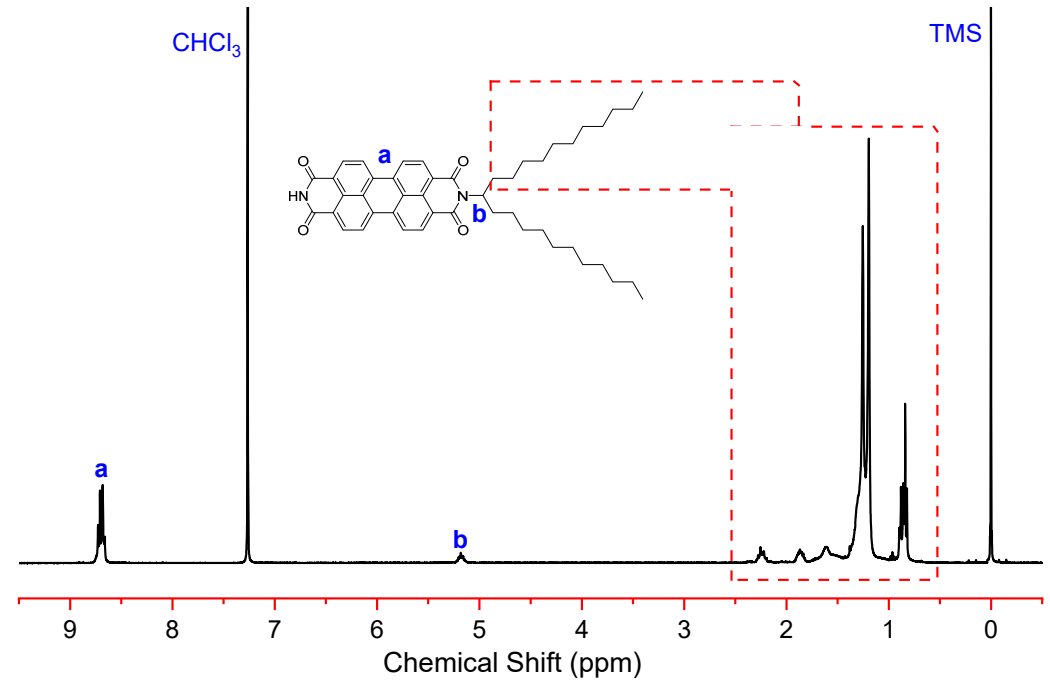

Figure S4. Molecular characterization of MPBI by ${ }^{1} \mathrm{H}$ NMR spectrum. 


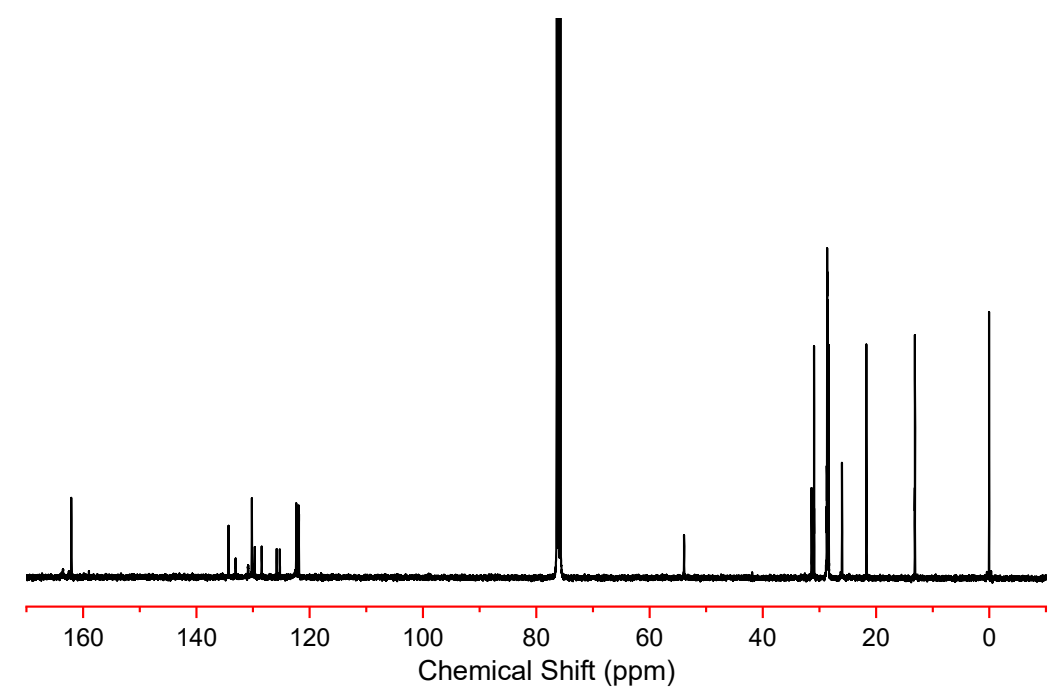

Figure S5. Molecular characterization of MPBI by ${ }^{13} \mathrm{C}$ NMR spectrum.

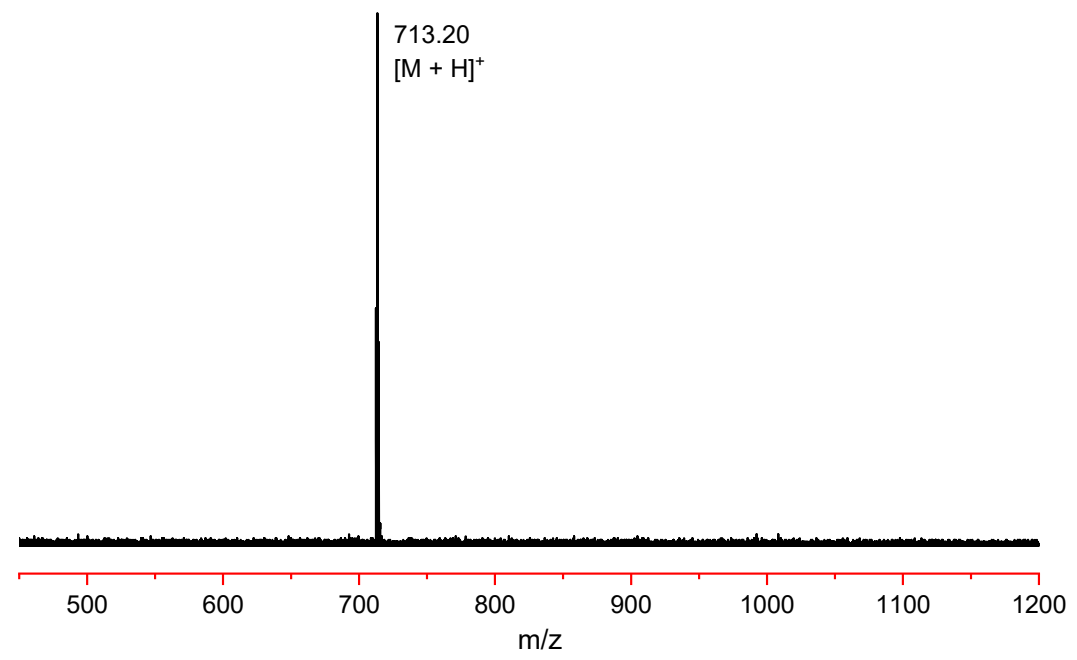

Figure S6. Molecular characterization of MPBI by MALDI-TOF-MS spectrum.

Hydrogen-bonded TCS-MPBI supramolecular complex. Two components of TCS and MPBI compounds with a molar ratio of 1:3 were dissolved in chloroform. The resulting solution was allowed for stirring for several hours before solvent evaporation under reduced pressure. The obtained TCSMPBI supramolecular complex was finally dried in vacuum overnight. The formation of supramolecular complex was verified by ${ }^{1} \mathrm{H}$ and ${ }^{13} \mathrm{C}$ NMR analysis, which were displayed as follows. 


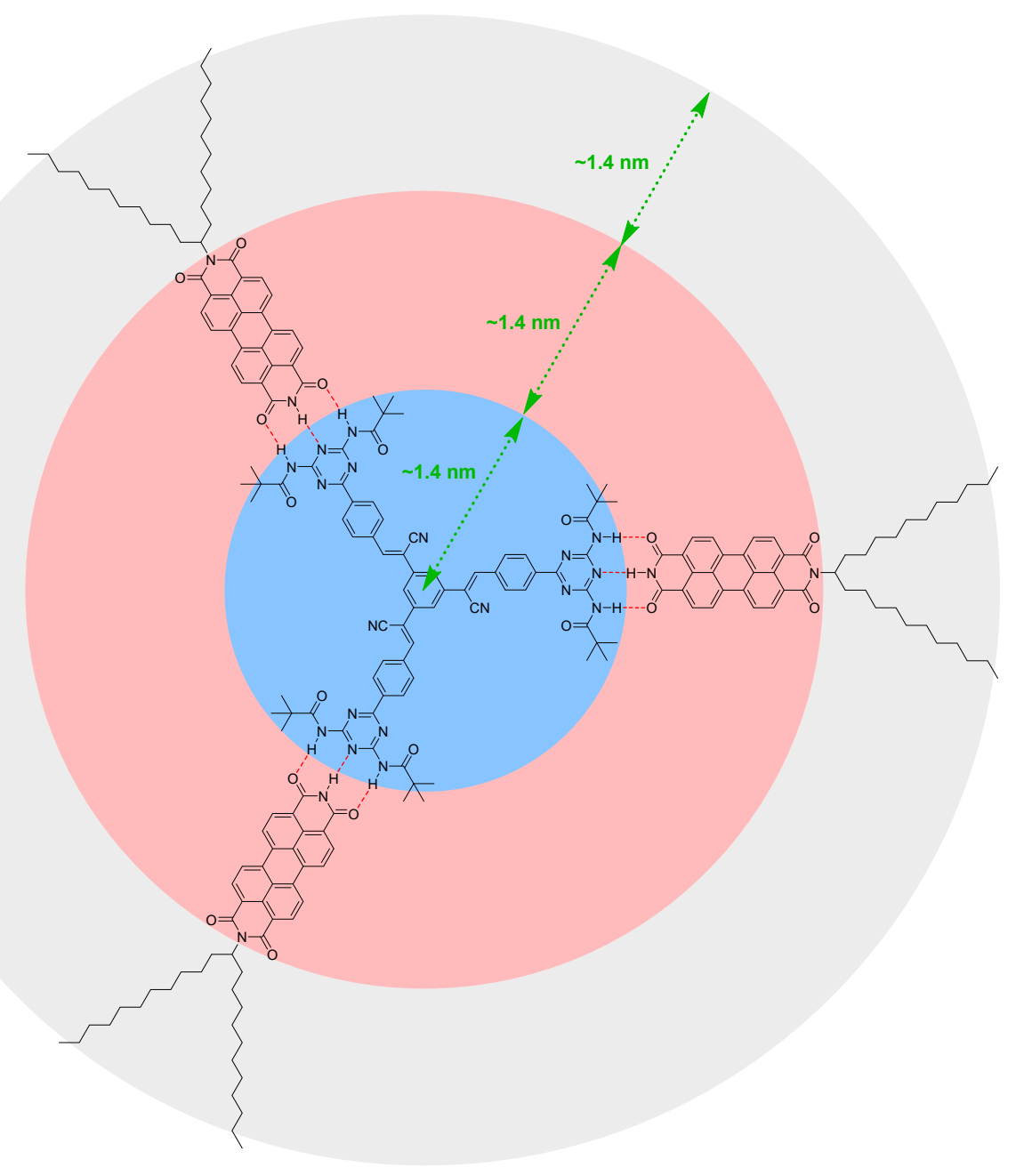

Scheme S3. Illustration of the hydrogen-bonded TCS-MPBI supramolecular complex.

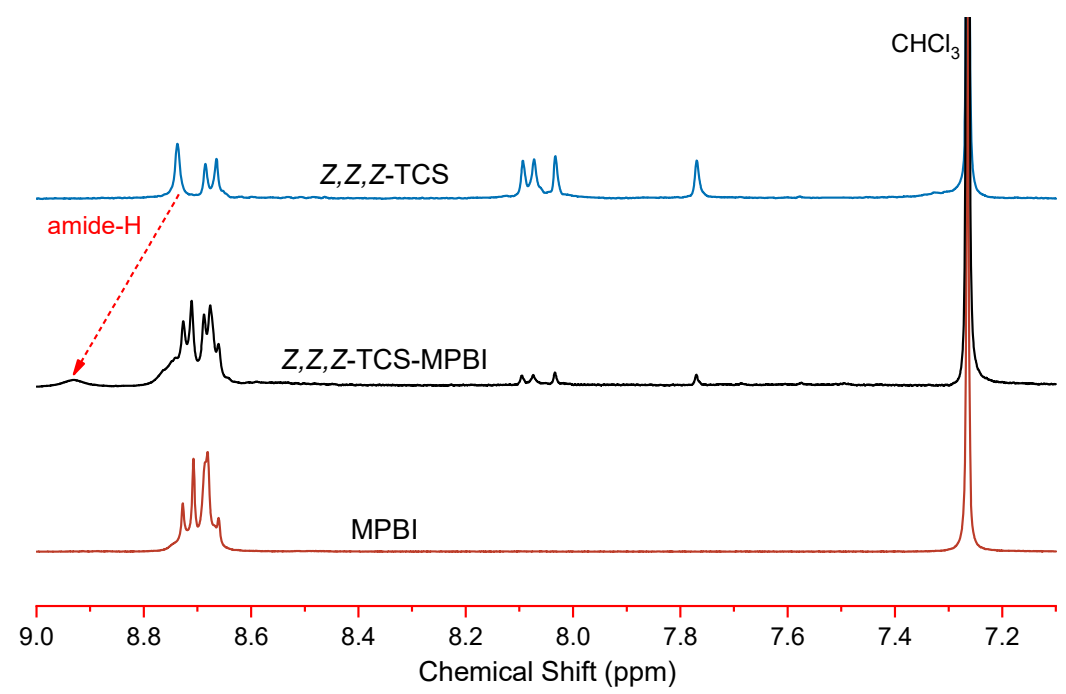

Figure S7. Comparison of ${ }^{1} \mathrm{H}$ NMR spectra for identifying the formation of hydrogen-bonded $Z, Z, Z$ TCS-MPBI supramolecular complex. 


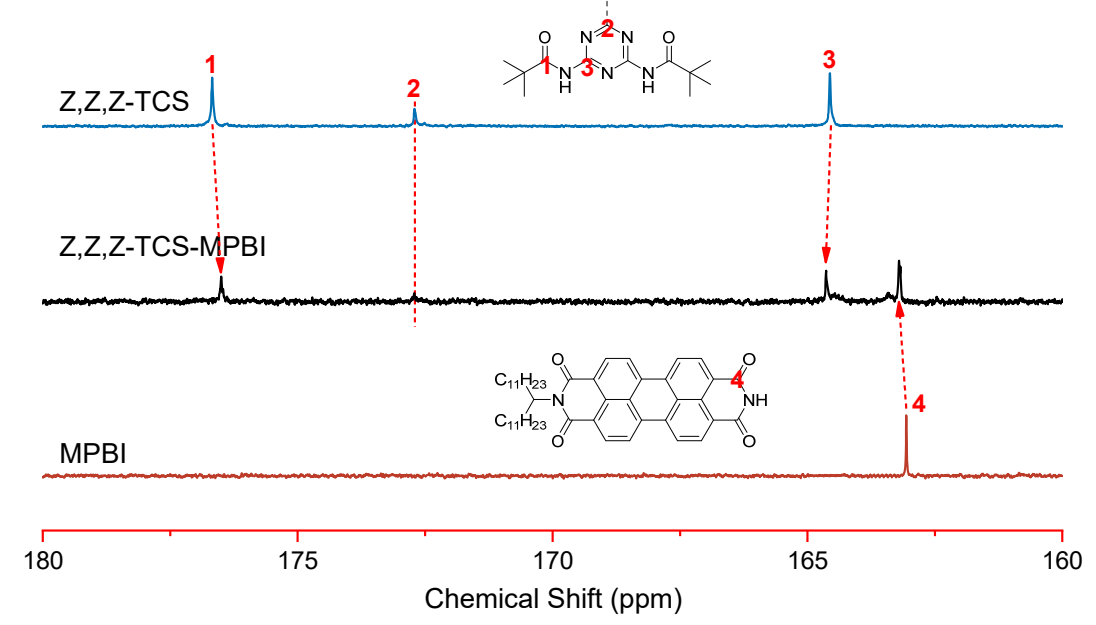

Figure S8. Comparison of ${ }^{13} \mathrm{C}$ NMR spectra for identifying the formation of hydrogen-bonded $Z, Z, Z$ TCS-MPBI supramolecular complex.
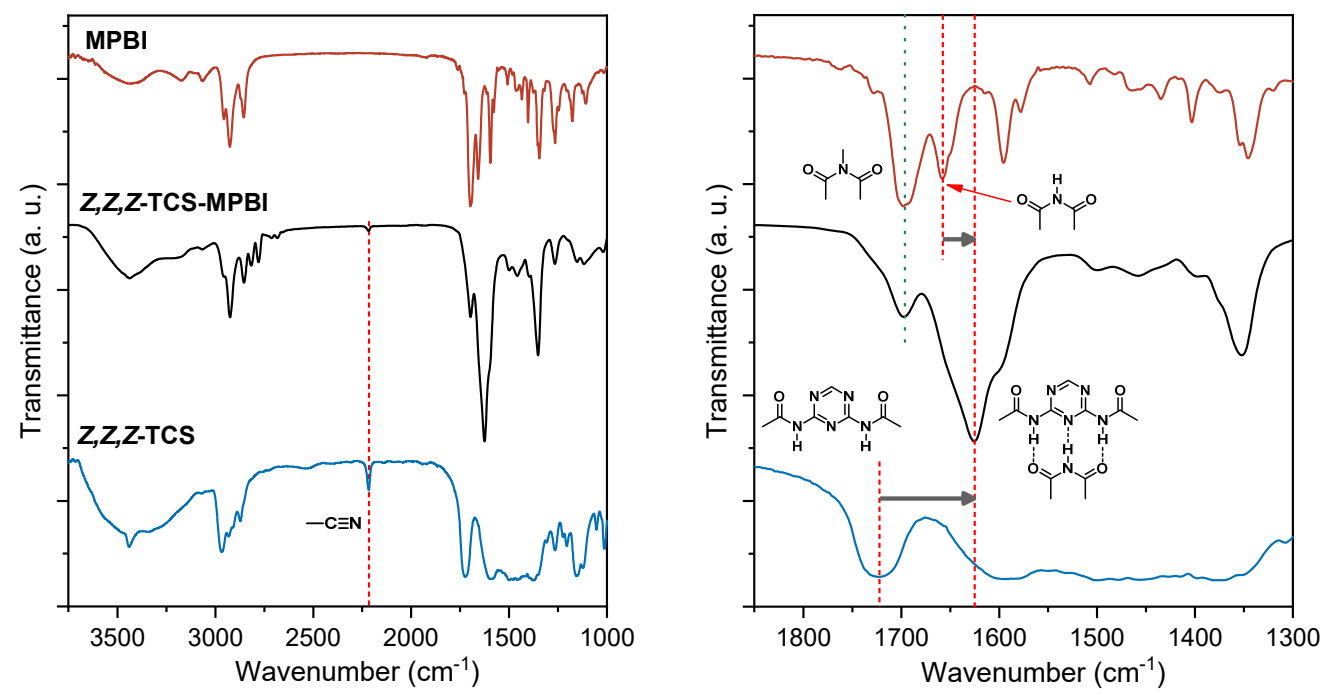

Figure S9. Comparison of FT-IR spectra for identifying the formation of hydrogen-bonded Z,Z,ZTCS-MPBI supramolecular complex. The $\mathrm{C}=\mathrm{O}$ stretching vibration of amide group in $Z, Z, Z-T C S$ is at $1722 \mathrm{~cm}^{-1}$, while the $\mathrm{C}=\mathrm{O}$ stretching vibration of imide group in MPBI is at $1657 \mathrm{~cm}^{-1}$, both of which were broadened and merged into a single peak at a lower wavenumber of $1626 \mathrm{~cm}^{-1}$ for Z,Z,ZTCS-MPBI, suggesting the successful complexation of Z,Z,Z-TCS and MPBI via hydrogen-bonding interactions. 


\section{Thermal Properties of the Supramolecular Complexes}

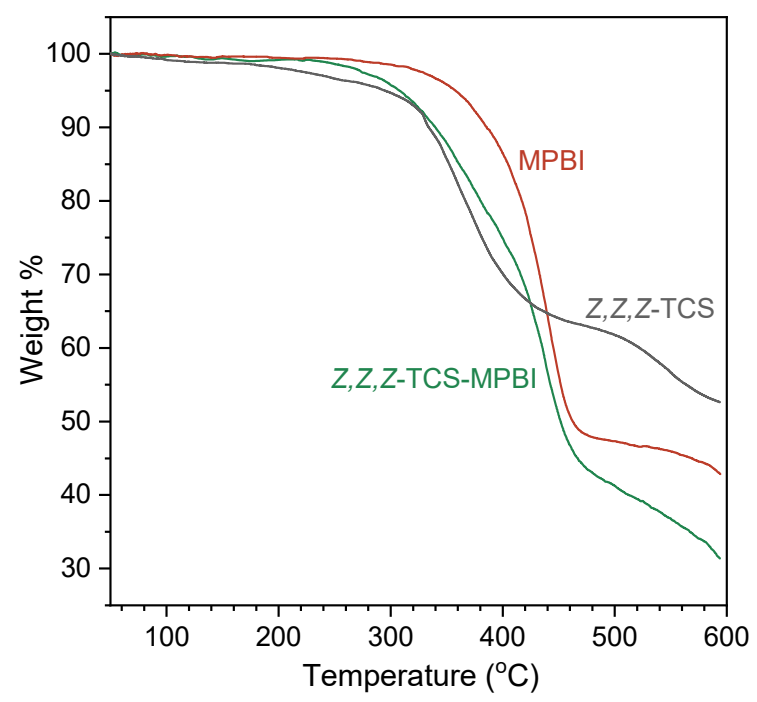

Figure S10. TGA curves collected from $Z, Z, Z$-TCS and MPBI compounds and their hydrogen-bonded $Z, Z, Z$-TCS-MPBI supramolecular complexes at a scanning rate of $20{ }^{\circ} \mathrm{C} \mathrm{min}^{-1}$.

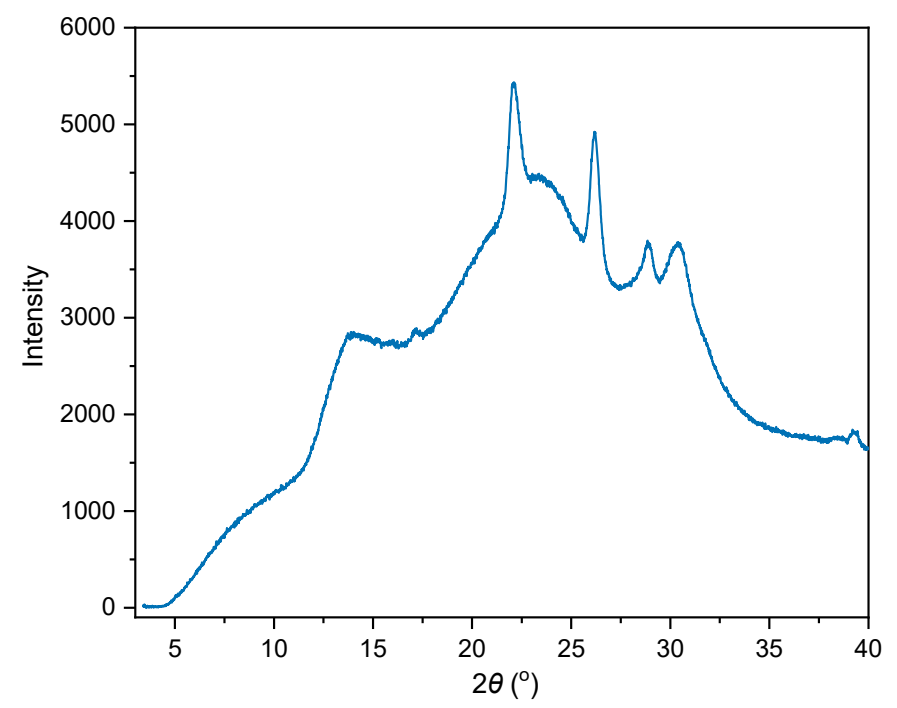

Figure S11. X-ray diffractogram of MPBI compound. 


\section{Photo-Isomerization of the TCS Compound and TCS-MPBI Complex}

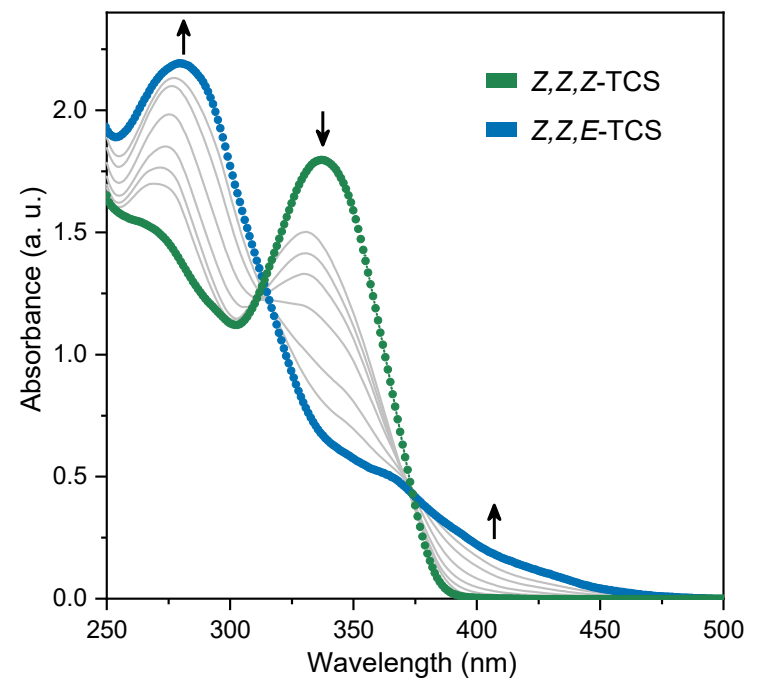

Figure S12. UV-Vis absorption spectra evolution upon $365 \mathrm{~nm}$ UV irradiation of TCS in dichloromethane solution $\left(1 \times 10^{-5} \mathrm{~mol} / \mathrm{L}\right)$, the arrows indicating the intensity changing direction with irradiation duration.

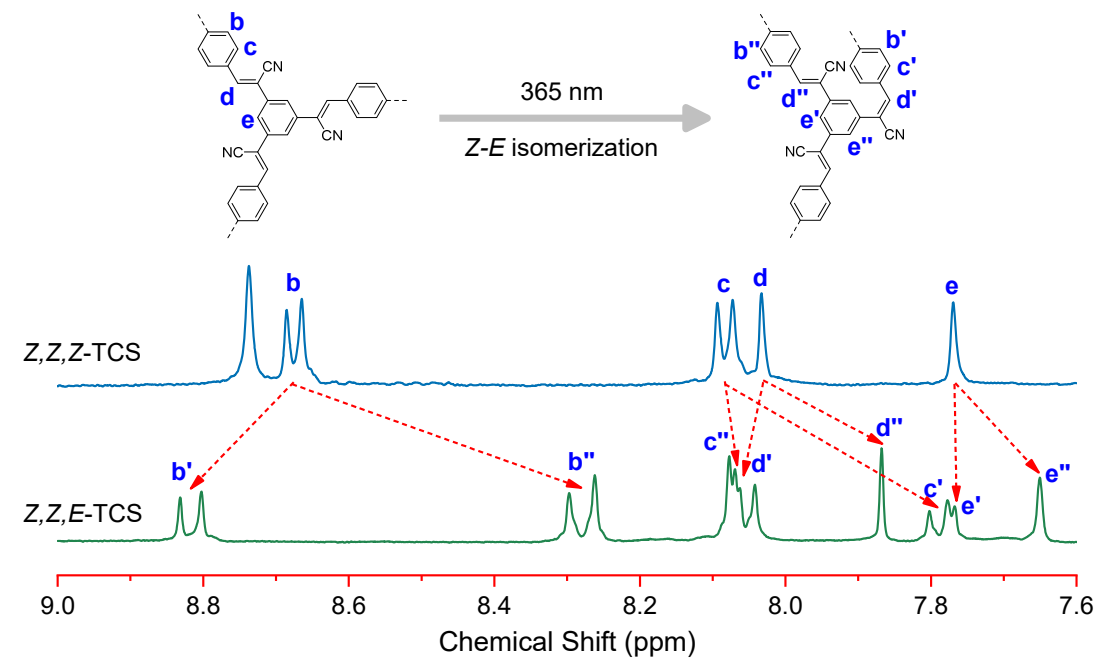

Figure S13. Comparison of ${ }^{1} \mathrm{H}$ NMR spectra in $\mathrm{CDCl}_{3}$ for illustrating the photo-isomerization from $Z, Z, Z-\mathrm{TCS}$ to $Z, Z, E-\mathrm{TCS}$. 


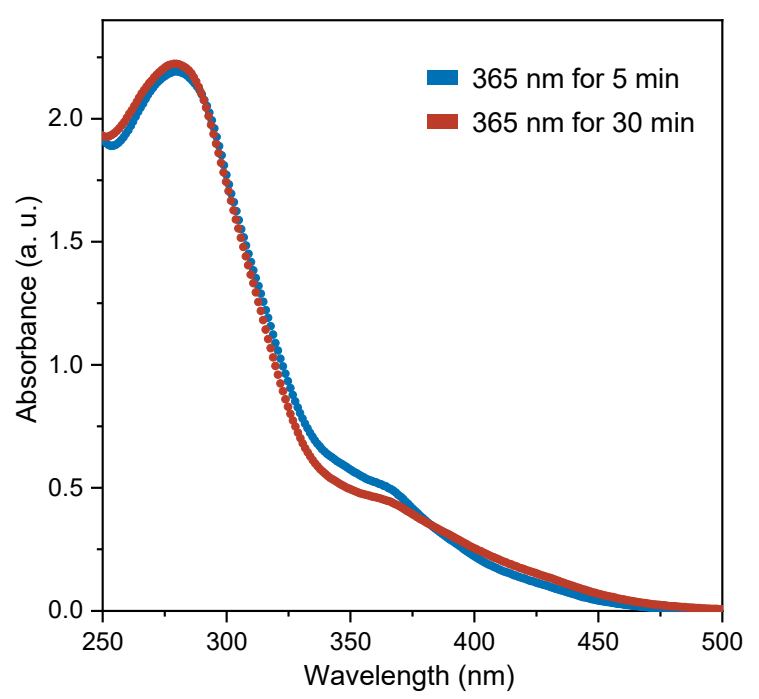

Figure S14. UV-Vis absorption spectra of TCS in dichloromethane solution $\left(1 \times 10^{-5} \mathrm{~mol} / \mathrm{L}\right)$ upon 365 nm UV irradiation for different times.

The ultraviolet-visible (UV-Vis) absorption peak of Z,Z,Z-isomer at around $337 \mathrm{~nm}$ decreased, and two new peaks at about 280 and $410 \mathrm{~nm}$ emerged and gradually enhanced (Figure S12). The obtained isomer was further confirmed by ${ }^{1} \mathrm{H}$ NMR spectroscopy (Figure S13), which revealed that only one of the three cyanostilbene arms of TCS underwent Z-E isomerization, leading to the formation of Z,Z,E-TCS. Even after prolonged UV irradiation, the UV-Vis spectra exhibited no significant change (Figure S14), manifesting Z,Z,E-TCS has reached the photostationary state.

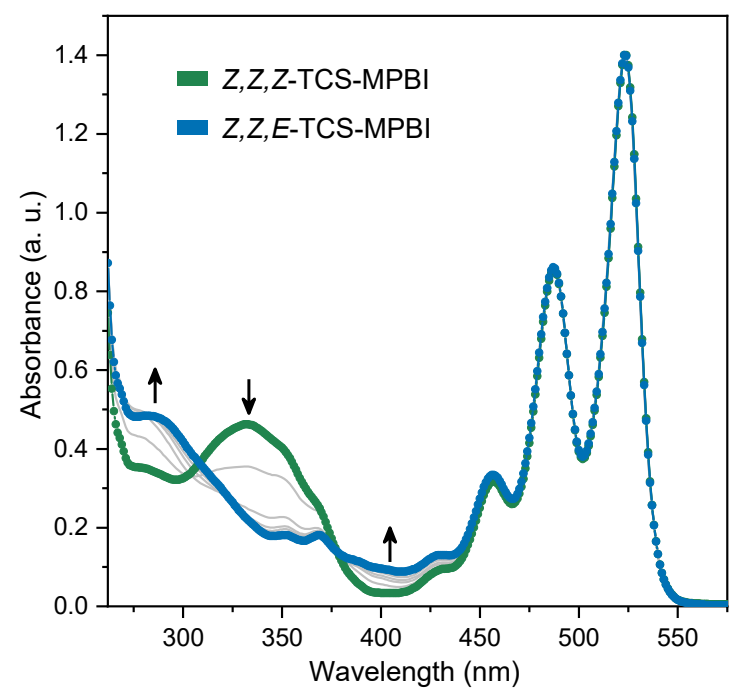

Figure S15. UV-Vis absorption spectra evolution upon $365 \mathrm{~nm}$ UV irradiation of TCS-MPBI in dichloromethane solution $\left(2 \times 10^{-6} \mathrm{~mol} / \mathrm{L}\right)$, the arrows indicating the intensity changing direction with irradiation duration. 
Table S1. HOMO and LUMO distribution and molecular energy level of MPBI and TCS compound.

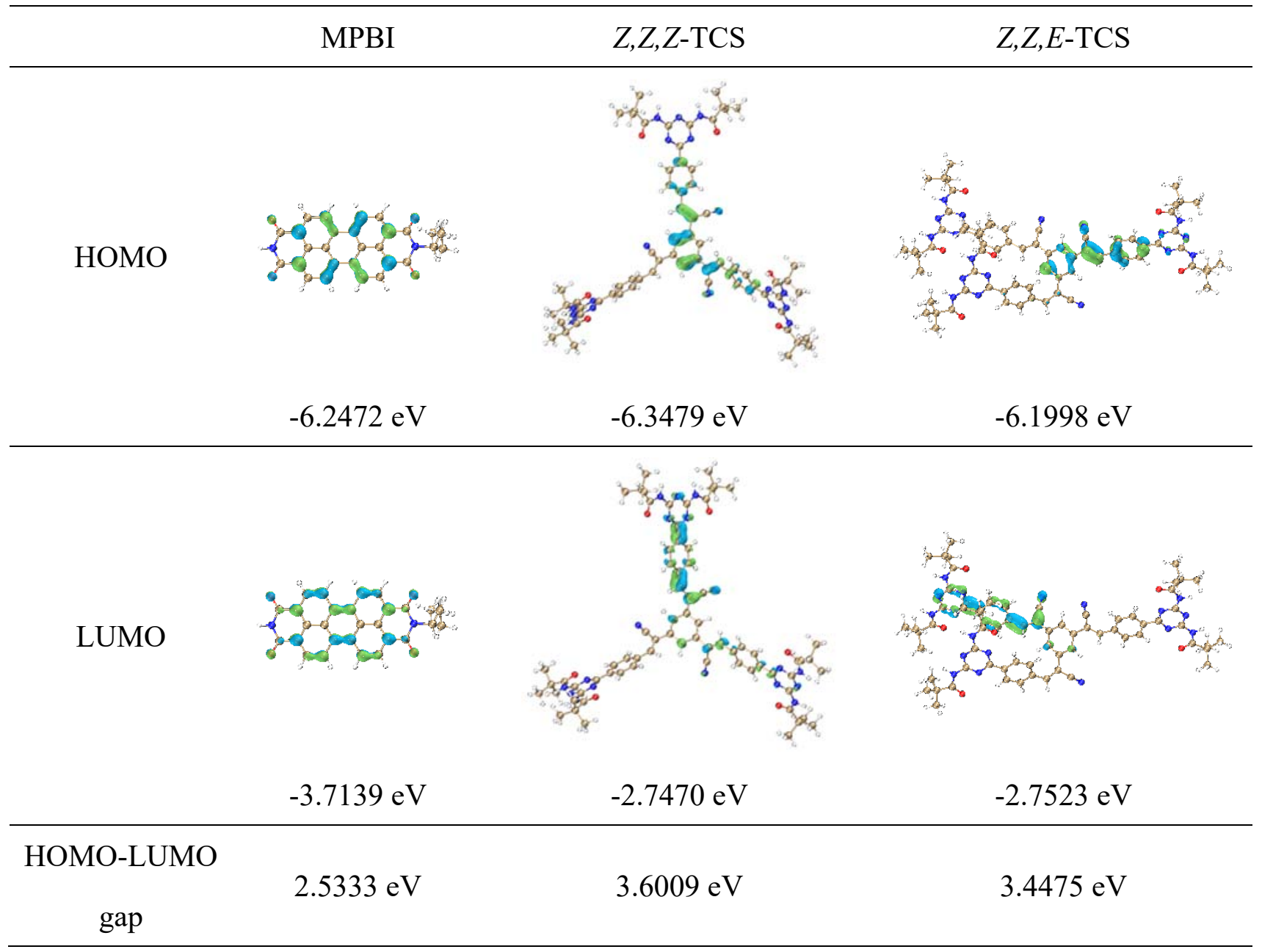

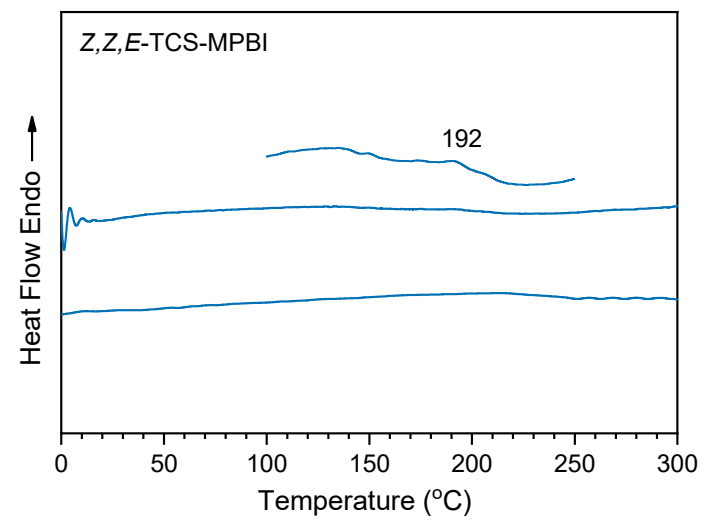

Figure S16. DSC thermogram of Z,Z,E-TCS-MPBI supramolecular complex at a scanning rate of $10{ }^{\circ} \mathrm{C} \min ^{-1}$. 


\section{Fluorescent Properties of TCS-MPBI Supramolecular Complexes}

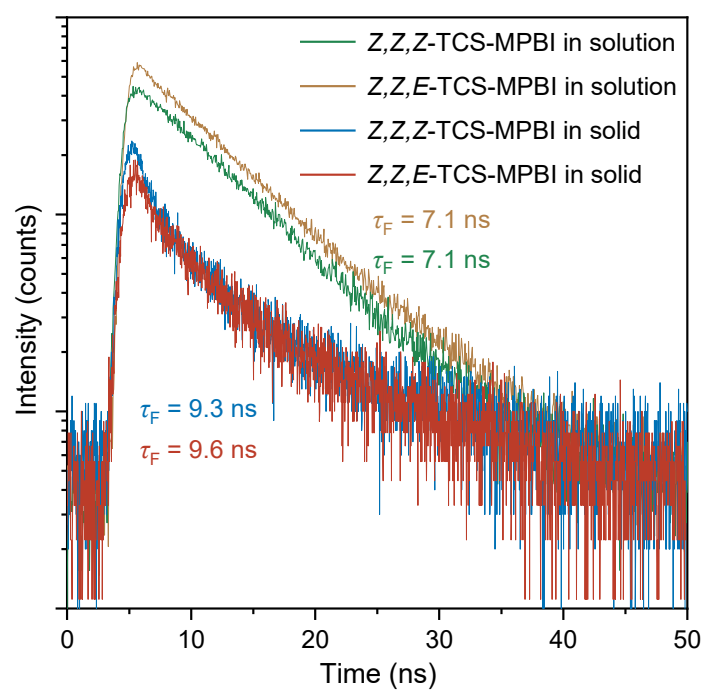

Figure S17. Time-resolved fluorescence decay profiles of TCS-MPBI supramolecular complexes in both solution and solid state.

Table S2. Emission properties comparison for TCS-MPBI complex in both solution and solid state.

\begin{tabular}{ccccc}
\hline Samples & $\Phi_{\mathrm{F}}$ & $\tau$ & $k_{\mathrm{r}}=\Phi_{\mathrm{F}} / \tau$ & $k_{\mathrm{nr}}=\left(1-\Phi_{\mathrm{F}}\right) / \tau$ \\
\hline$Z, Z, Z$-TCS-MPBI solution & $97 \%$ & $7.1 \mathrm{~ns}$ & $13.7 \times 10^{7} \mathrm{~s}^{-1}$ & $0.4 \times 10^{7} \mathrm{~s}^{-1}$ \\
$Z, Z, E-\mathrm{TCS}-\mathrm{MPBI}$ solution & $97 \%$ & $7.1 \mathrm{~ns}$ & $13.7 \times 10^{7} \mathrm{~s}^{-1}$ & $0.4 \times 10^{7} \mathrm{~s}^{-1}$ \\
$Z, Z, Z$-TCS-MPBI solid & $10 \%$ & $9.3 \mathrm{~ns}$ & $1.1 \times 10^{7} \mathrm{~s}^{-1}$ & $9.7 \times 10^{7} \mathrm{~s}^{-1}$ \\
$Z, Z, E-\mathrm{TCS}-\mathrm{MPBI}$ solid & $4 \%$ & $9.6 \mathrm{~ns}$ & $0.4 \times 10^{7} \mathrm{~s}^{-1}$ & $10.0 \times 10^{7} \mathrm{~s}^{-1}$ \\
\hline
\end{tabular}

